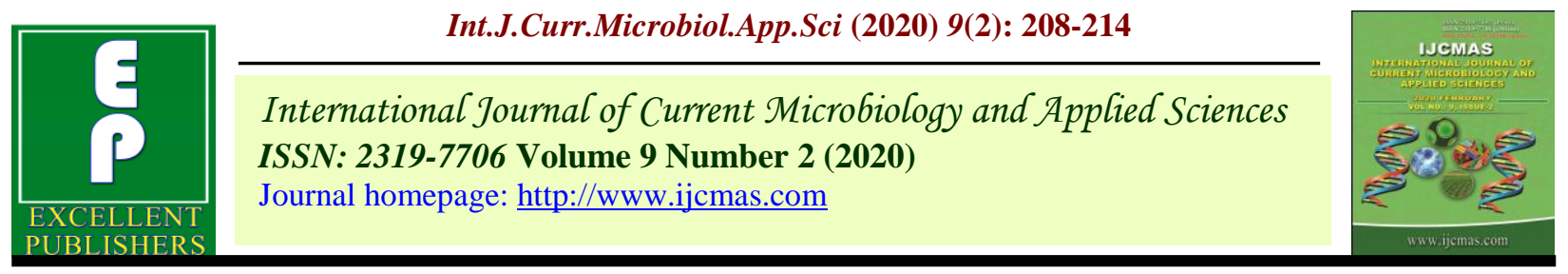

Original Research Article

https://doi.org/10.20546/ijcmas.2020.902.026

\title{
Sensory Attributes of Sunflower Microgreens with Storage under Ethanol Vapour and Organic Acid Treatments
}

\author{
Nidhi Dalal ${ }^{1}$, Saleem Siddiqui ${ }^{1}$ and Neeraj $^{1}{ }^{*}$ \\ ${ }^{1}$ Centre of food Science and Technology, Chaudhary Charan Singh Haryana Agriculture \\ University, Hisar-125004, Haryana (India) \\ *Corresponding author
}

Keywords

Sunflower,

Microgreens,

Ethanol vapour,

Organic acid

Article Info

Accepted:

05 January 2020

Available Online:

10 February 2020

A B S T R A C T

Sunflower microgreens hold potential to bring fresh food to consumers with minimal input and maximal nutritional benefit. The study involved use of GRAS treatments to increase the shelf life of sunflower microgreens. Microgreens were treated to 5 treatments, viz. ethanol vapour (EV), citric acid spray (CA), ascorbic acid spray (AA), citric acid+ethanol spray $(\mathrm{CA}+\mathrm{E})$ and citric acid+ascorbic acid spray $(\mathrm{CA}+\mathrm{AA})$ and distilled water as control, under LDPE packaging. They were evaluated organoleptically for color and appearance, taste, aroma, texture and overall acceptability by a team of semi-trained professionals using 9-point hedonic scale. CA+AA and control maintained highest quality of microgreens with respect to taste, texture, aroma and overall acceptability. EV and $\mathrm{CA}+\mathrm{E}$ had an adverse effect on the quality during later stages of storage with production of offodour and loss of taste and color. Thus organic acid treatments can be used to improve the shelf-life of sunflower microgreens without adversely affecting the sensory properties.

\section{Introduction}

Microgreens are young and tender leafy greens available in varying palette of colors, textures and flavors. They have three basic parts: a central stem, pair of cotyledonary leaves and very young first pair of true leaves. They require minimal input for growth and have a growth period of 6-10 days (Dalal 2016; Dalal et al., 2019). Crops with easy germination have potential to be consumed as microgreens. They can be grown at homes and urban setups with constraint for space. Microgreens contain higher concentrations of bioactive compounds such as vitamin $\mathrm{C}$, vitamin $\mathrm{K}$, vitamin $\mathrm{E}$, beta-carotene and carotenoids than their mature counterparts (Xiao at al., 2014a,b). They can thus be referred to as "functional foods". Owing to their high nutrition potential and ease of 
production, they also have potential to serve as a wholesome food in space for astronauts (Johnson, 2019).

Sunflower seedscontain $24 \%$ to $30 \%$ protein and are rich in 8 essential amino acids. Sunflower microgreens, however, are a richer source of vitamins, protein and amino acids than the dry seeds due to action of enzymes that takes place while germination. The concentration of essential amino acids, especially tryptophan and lysine increases greatly during germination (Balasaraswathi and Sadasivam, 1997). Sunflower microgreens are also rich in fibre, protein, total phenols (caffeic and protocatechuic acids), essential fatty acids and vitamins A, B complex, C, D and E and have high antioxidant capacity (Pajak et al., 2014; Dalal et al., 2019). They also contain minerals such as calcium, phosphorous, iron, iodine, potassium, magnesium and the trace elements zinc, manganese, copper and chromium (Tony F., 2014).

Sensory attributes are crucial in determining the acceptance of fresh produce among consumers. The outer appearance (color, smooth surface free from cuts, blemishes), aroma, texture and flavor determines the overall acceptability (Barrett et al., 2010). Color and appearance help in the first buy, while organoleptic properties such as flavor, aroma, mouthfeel determine the subsequent purchases (Francis et al., 2012; Barrett et al., 2010). Contemporary consumers are more aware about the health benefits of fresh foods and pay more attention to the nutritional aspects of the food they consume. Thus, nutritional and sensory properties, both play an important role in consumer acceptance. And microgreens have them both.

Like any other fresh leafy produce, sunflower microgreens have a short shelf life of 1-2 days. Applications of various GRAS (generally regarded as safe) chemicals like ethanol vapours, various antioxidants like citric and ascorbic acids and their combinations have been reported to extend the shelf life of minimally processed fruits and vegetables (Goyal et al., 2014; Chandra et al., 2012). MAP (modified atmosphere packaging has been shown to extend the shelf life of fresh produce as it lowers respiration, delay ripening, prevent off-odour and flavour build-up, retard discoloration and hinder the growth of spoilage microorganisms (Xiao et al., 2014a,b; Zhu and Gao, 2017).

While ample research data is available for sensory properties of fresh cut fruits and vegetables, limited studies have been published about sensory properties of microgreens. This work is attempt to throw some light on sensory attributes of sunflower microgreens with storage time and how organoleptic qualities might differ with chemical treatments.

\section{Materials and Methods}

Sunflower (Helianthus annus L.) seeds of variety "64-A-57 Pioneer" were procured from Department of Oilseeds Technology, CCS HAU, Hisar for growing microgreens. The chemicals used in this investigation were analytical grade reagents from Sigma-Aldrich Pvt. Ltd. New Delhi (India).

\section{Growing conditions, treatments and storage}

The seeds of sunflower were washed with tap water to remove adhering dirt and soaked in tap water for $24 \mathrm{~h}$. Wet seeds were evenly distributed over the wet surface of vermiculite filled in plastic trays kept in shade house at 25 $\pm 5^{\circ} \mathrm{C}$. The crop was kept moist until harvest and no fertilizer/pesticide was applied. Microgreens were harvested after 7 days of growth, washed with tap water and subjected to the treatments at room temperature: 


\section{Treatment}

Ethanol vapour treatment (EV)

Citric acid spray treatment (CA)

Ascorbic acid spray treatment (AA)

Citric acid + Ethanol treatment $(\mathrm{CA}+\mathrm{E})$
Concentration and duration (min)

$100 \%$ for 3.5 minutes

$0.5 \% \mathrm{w} / \mathrm{v}(100 \mathrm{ml} / \mathrm{kg})$

$0.5 \% \mathrm{w} / \mathrm{v}(100 \mathrm{ml} / \mathrm{kg})$

$0.5 \% \mathrm{w} / \mathrm{v}+40 \% \mathrm{v} / \mathrm{v}$ resp. $(100 \mathrm{ml} / \mathrm{kg})$

$0.25 \% \mathrm{w} / \mathrm{v}$ each $(100 \mathrm{ml} / \mathrm{kg})$

Citric acid + Ascorbic acid spray treatment $(\mathrm{CA}+\mathrm{AA})$

The duration and concentration of vapour and spray treatment was calculated and decided after pre-trails. Sunflower microgreens were treated to varying concentrations of sprays and varying time periods of vapours and the ones with the best sensory results was chosen for final testing.

The vapour chamber was saturated with the ethanol vapour and microgreens were subjected to EV treatment for given $3.5 \mathrm{~min}$. For spray treatments of $\mathrm{CA}, \mathrm{AA}, \mathrm{CA}+\mathrm{E}$ and $\mathrm{CA}+\mathrm{AA}$, solutions of required strength were prepared and sprayed on microgreens. The excess of solution was drained out and the microgreens were allowed to dry in air for 30 min. Water was taken as control. The microgreens from each treatment were packed either in $0.05 \%$ perforated LDPE bags. Filter paper soaked with water was placed at the bottom of the bag to maintain high humidity. Packs were stored for 16 days at low temperature $\left(10 \pm 1{ }^{\circ} \mathrm{C}\right)$ maintained in B.O.D. (Biological oxygen demand) incubator having three replicates with sampling at every $4^{\text {th }}$ day.

\section{Sensory analysis of sunflower microgreens}

Sunflower microgreens were subjected to sensory evaluation for color, texture, taste, aroma and overall acceptability attributes by 10 semi trained panellists using 9-point Hedonic scale. The overall rating was obtained by averaging the score given by the panellists.

\section{Statistical analysis}

The data obtained in the present investigation were subjected to analysis of variance
(ANOVA) techniques and analysed according to three factorial completely randomized design (CRD). The critical difference (CD) value at 5 per cent level was used for making comparison among different treatments during storage period.

\section{Results and Discussion}

\section{Color and appearance}

Table 1 shows the color and appearance scores of sunflower microgreen subjected to chemical treatments over a period of 16 days. Color and appearance score decreased progressively with storage from 7.81 on zero day to 5.0 on $16^{\text {th }}$ day of storage. The microgreens were of acceptable color and appearance till $4^{\text {th }}$ day of storage in all the treatments, except control which maintained color and appearance till $12^{\text {th }}$ day. Treatments had a significant effect on color and appearance, with CA maintaining best color and appearance apart from control. The interactions between various treatments and storage were found to be significant. The decrease in color and appearance of sunflower microgreens can be due to degradation of pigments with time. Chlorophyll and carotenoids have been reported to get degraded with storage period, even at low temperature (Xiao et al., 2014a,b).Similar results were reported by Xiao et al., (2014b) 
in radish microgreen stored under MAP at low temperature.

\section{Taste}

Taste scores of sunflower microgreen during storage subjected to treatments is presented in Table 2. Taste scores declined progressively with storage with 8.57 on zero day to 5.14 on $16^{\text {th }}$ day. They showed acceptable scored till $8^{\text {th }}$ day in all treatments. CA+AA exhibited the highest taste score on $8^{\text {th }}$ day followed by $\mathrm{EV}$ and control. The interactions between treatments and storage were found to be significant whereas interaction between treatments were non-significant.

Table.1 Effect of treatments and storage on taste of microgreens

\begin{tabular}{|c|c|c|c|c|c|c|c|}
\hline & \multicolumn{9}{|c|}{ Treatments } \\
\hline Storage period (days) & Control & EV & CA & AA & CA+E & CA+AA & Mean \\
\hline $\mathbf{0}$ & 8.00 & 8.00 & 8.00 & 7.71 & 7.57 & 7.57 & 7.81 \\
\hline $\mathbf{4}$ & 7.29 & 7.00 & 7.29 & 7.57 & 7.71 & 7.29 & 7.36 \\
\hline $\mathbf{8}$ & 7.11 & 5.29 & 6.29 & 5.29 & 5.29 & 5.29 & 5.69 \\
\hline $\mathbf{1 2}$ & 7.00 & 5.00 & 5.71 & 5.86 & 5.29 & 5.00 & 5.64 \\
\hline $\mathbf{1 6}$ & 5.00 & 5.00 & 5.00 & 5.00 & 5.00 & 5.00 & 5.00 \\
\hline Mean & 6.88 & 6.06 & 6.46 & 6.29 & 6.17 & 6.03 & \\
\hline CD at 5\% & Treatment: 0.213 & Storage: 0.194 & \multicolumn{5}{|c|}{ Treatment $\times$ storage: 0.476} \\
\hline
\end{tabular}

Table.2 Effect of treatments and storage on color and appearance of microgreens

\begin{tabular}{|c|c|c|c|c|c|c|c|}
\hline & \multicolumn{9}{|c|}{ Treatments } \\
\hline Storage period (days) & Control & EV & CA & AA & CA+E & CA+AA & Mean \\
\hline $\mathbf{0}$ & 8.43 & 8.43 & 9.00 & 8.57 & 8.57 & 8.43 & 8.57 \\
\hline $\mathbf{4}$ & 8.00 & 7.43 & 7.29 & 8.00 & 8.00 & 8.00 & 7.79 \\
\hline $\mathbf{8}$ & 7.57 & 7.57 & 7.43 & 7.43 & 7.29 & 7.71 & 7.50 \\
\hline $\mathbf{1 2}$ & 6.00 & 6.00 & 6.29 & 6.43 & 6.29 & 6.43 & 6.24 \\
\hline $\mathbf{1 6}$ & 5.00 & 5.00 & 5.43 & 5.43 & 5.00 & 5.00 & 5.14 \\
\hline Mean & 7.00 & 6.89 & 7.09 & 7.17 & 7.03 & 7.11 & \\
\hline CD at 5\% & Treatment: NS & Storage: 0.179 & Treatment $\times$ storage: 0.439 \\
\hline
\end{tabular}

Table.3 Effect of treatments and storage on texture of microgreens

\begin{tabular}{|c|c|c|c|c|c|c|c|}
\hline & \multicolumn{7}{|c|}{ Treatments } \\
\hline Storage period (days) & Control & EV & CA & AA & CA+E & CA+AA & Mean \\
\hline $\mathbf{0}$ & 8.57 & 8.57 & 8.57 & 8.57 & 8.57 & 8.57 & 8.57 \\
\hline $\mathbf{4}$ & 7.29 & 7.29 & 7.29 & 7.29 & 7.29 & 7.29 & 7.29 \\
\hline $\mathbf{8}$ & 6.71 & 6.57 & 7.00 & 7.00 & 7.00 & 7.00 & 6.88 \\
\hline $\mathbf{1 2}$ & 6.00 & 6.00 & 7.29 & 6.29 & 6.43 & 6.43 & 6.41 \\
\hline $\mathbf{1 6}$ & 5.00 & 4.29 & 4.29 & 4.29 & 4.71 & 4.29 & 4.48 \\
\hline Mean & 6.71 & 6.54 & 6.89 & 6.69 & 6.80 & 6.71 & \\
\hline CD at 5\% & Treatment: 0.209 & Storage: 0.191 & Treatment $\times$ storage: 0.468 \\
\hline
\end{tabular}


Table.4 Effect of treatments and storage on aroma of microgreens

\begin{tabular}{|c|c|c|c|c|c|c|c|}
\hline & \multicolumn{7}{|c|}{ Treatments } \\
\hline Storage period (days) & Control & EV & CA & AA & CA+E & CA+AA & Mean \\
\hline $\mathbf{0}$ & 8.00 & 8.29 & 8.00 & 8.00 & 8.29 & 8.00 & 8.10 \\
\hline $\mathbf{4}$ & 7.00 & 7.43 & 7.00 & 7.00 & 7.00 & 7.00 & 7.07 \\
\hline $\mathbf{8}$ & 6.00 & 6.00 & 6.00 & 6.00 & 6.29 & 5.71 & 6.00 \\
\hline $\mathbf{1 2}$ & 6.00 & 5.71 & 6.00 & 6.00 & 6.29 & 5.57 & 5.93 \\
\hline $\mathbf{1 6}$ & 5.00 & 4.71 & 5.00 & 5.00 & 5.00 & 5.00 & 4.95 \\
\hline Mean & 6.40 & 6.43 & 6.40 & 6.40 & 6.57 & 6.26 & \\
\hline CD at 5\% & Treatment: 0.129 & Storage: 0.118 & Treatment $\times$ storage: 0.288 \\
\hline
\end{tabular}

Table.5 Effect of treatments and storage on overall acceptability of microgreens

\begin{tabular}{|c|c|c|c|c|c|c|c|}
\hline & \multicolumn{7}{|c|}{ Treatments } \\
\hline Storage period (days) & Control & EV & CA & AA & CA+E & CA+AA & Mean \\
\hline $\mathbf{0}$ & 8.25 & 8.32 & 8.39 & 8.21 & 8.25 & 8.14 & 8.26 \\
\hline $\mathbf{4}$ & 7.39 & 7.29 & 7.21 & 7.46 & 7.30 & 7.39 & 7.38 \\
\hline $\mathbf{8}$ & 6.75 & 6.36 & 6.68 & 6.43 & 6.46 & 6.43 & 6.52 \\
\hline $\mathbf{1 2}$ & 6.25 & 5.68 & 6.32 & 6.14 & 6.07 & 5.86 & 6.05 \\
\hline $\mathbf{1 6}$ & 5.00 & 4.75 & 4.93 & 4.93 & 4.93 & 4.82 & 4.89 \\
\hline Mean & 6.73 & 6.48 & 6.71 & 6.64 & 6.60 & 6.53 & \\
\hline CD at 5\% & Treatment: 0.144 & Storage: 0.132 & \multicolumn{2}{|c|}{ Treatment $\times$ storage: 0.372} \\
\hline
\end{tabular}

The changes in taste can be due to degradation of bioactive compounds in tissue with time and production of degradation intermediates with slight off-flavors. Dalal et al., (2020) reported similar trends in taste of sunflower microgreens, however, with different packaging material.

\section{Texture}

Texture scores of sunflower microgreens subjected to treatments during storage is presented in Table 3 . There was progressive decline in texture scores of microgreens during storage from 8.57 on zero day to 4.48 on $16^{\text {th }}$ day. The microgreens showed acceptable texture by $8^{\text {th }}$ day of storage in all the treatments, except EV which exhibited acceptable texture till $4^{\text {th }}$ day. Treatments and storage had significant effect on texture and do did the interaction between storage and treatment. Plant materials contain a significant amount of water and other liquidsoluble materials surrounded by a semipermeable membrane and cell wall. The texture of fruits and vegetables is derived from their turgor pressure, and the composition of individual plant cell walls and the middle lamella (Barrett et al., 2010). The decrease in texture score can be attributed to loss of moisture in fresh produce with time and degradation of polysaccharide components with storage period and loss of turgor pressure with due to loss of water (Xiao et al., 2014b; Zhu and Gao, 2017).

\section{Aroma}

Table 4 shows the aroma scores of sunflower microgreens subjected to treatments under 
storage. Aroma scores exhibited a progressive decline with time from 8.10 on zero day to 4.95 on $16^{\text {th }}$ day. Aroma scores were acceptable in all treatments upto $8^{\text {th }}$ day of storage, except CA+AA which had acceptable score till $4^{\text {th }}$ day only. Storage and treatment had significant effect on aroma score, and so did the interaction between the two.Chandra et al., (2012) reported higher off-odour and lower sensory quality of microgreens treated with chlorine, citric acid + ascorbic acid, citric acid + ethanol and water washed samples. Xiao et al., (2014b) also reported an increase in off-odour of radish microgreens under MAP during a 16-day storage period and Xiao et al., (2014a) also reported similar results for radish microgreens under MAP at differing temperatures during 28-day storage. This was attributed to anaerobic respiration due to $\mathrm{CO}_{2}$ accumulation and $\mathrm{O}_{2}$ depletion. Zhu and Gao (2017) reported similar results in Chinese to on tender shoots under MAP storage.

\section{Overall acceptability}

Table 5 shows the overall acceptability scores of sunflower microgreens subjected to treatments under storage. The overall acceptability progressively declined from 8.31 on zero day to 6.52 on $16^{\text {th }}$ day. Sunflower microgreens had acceptable score till $4^{\text {th }}$ day of storage. $\mathrm{CA}+\mathrm{AA}$ and $\mathrm{CA}+\mathrm{E}$ had the least scores. Storage and treatments had significant effect on overall acceptability score, and so did the interaction between the storage and treatment. Treatment AA maintained highest overall acceptability of microgreens till $4^{\text {th }}$ day of storage followed by $\mathrm{CA}+\mathrm{AA}$ and control. The decline in overall acceptability can be attributed to decline in color and appearance, texture, aroma and taste, as evident by the above results. Microgreens, being a fresh produce lose their taste, texture and appearance with time due to irreversible internal biochemical changes. Dalal et al.,
(2020) reported similar trend with sunflower microgreens packed in polystyrene trays and the quality was maintained till $12^{\text {th }}$ day of storage. Xiao et al., (2014a,b) reported similar trends with radish microgreens stored for 16 and 24 days respectively under MAP at low temperature. Zhu and Gao (2017) also reported similar results in Chinese toon tender shoots packed under MAP and low temperature

In conclusion, sunflower microgreens present an excellent opportunity as edible fresh produce that can be consumed without processing or with minimal processing. Organic acids and washing with distilled water was sufficient to extend the shelf-life of sunflower microgreens packed in LDPE bags for 8 days. More studies are required regarding the sensory qualities, use of other GRAS chemicals and packaging materials with focus on microbiological aspect of sunflower microgreens. Use of pre-treatments like $\mathrm{CaCl}_{2}$ can be explored to get higher biomass and Plant hormones to change the flavor profile. Flavor profile can also be altered by studying and maintaining the biochemical reactions in the microgreen tissue using films, MAP, treatments and light/dark storage. Microgreens hold a true potential to bring fresh food to the consumers with minimal input and maximum nutritional benefits.

\section{References}

Balasaraswathi, R. and Sadasivam, S. (1997). Changes in oil, sugars and nitrogenous components during germination of sunflower seeds, Helianthus annuus. Plant Foods for Human Nutrition, 51, 71-77.

Barrett, D. M., Beaulieu, J. C., and Shewfelt, R. (2010). Color, flavor, texture, and nutritional quality of fresh-cut fruits and vegetables: desirable levels, 
instrumental and sensory measurement, and the effects of processing. Critical reviews in food science and nutrition, 50(5), 369-389.

Chandra, D., Kim, J. G. and Kim, Y. P. (2012). Changes in microbial population and quality of microgreens treated with different sanitizers and packaging films. Horticulture, Environment and Biotechnology, 53(1), 32-40.

Dalal, N. (2016). Studies on extending shelf life of sunflower (helianthus annus L.) microgreen (Doctoral dissertation, CCSHAU).

Dalal, N., Siddiqui, S. and Neeraj (2019). Effect of chemical treatment, storage and packaging on physio-chemical properties of sunflower microgreen. International Journal of Chemical Studies, 7(5): 1046-1050.

Dalal, N., Siddiqui, S. and Neeraj (2020). Evaluation of effects of chemical treatments on sensory attributes of sunflower microgreens with storage. Journal of Pharmacognosy and Phytochemistry, 9(1):439-443.

Francis, G. A., Gallone, A., Nychas, G. J., Sofos, J. N., Colelli, G., Amodio, M. L., and Spano, G. (2012). Factors affecting quality and safety of freshcut produce. Critical reviews in food science and nutrition, 52(7), 595-610.

Goyal, A. Siddiqui, S. Upadhyay, N. and Soni, J. (2014). Effects of ultraviolet irradiation, pulsed electric field, hot water and ethanol vapours treatment on functional properties of mung bean sprouts. Journal of Food Science and Technology, 51(4), 708-714.

Johnson, C. M. (2019). Microgreens for Human Nutrition in Spaceflight.

Pajak, P. Socha, R. Gałkowska, D. Roznowski, J. and Fortuna, T. (2014). Phenolic profile and antioxidant activity in selected seeds and sprouts. Food Chemistry, 143, 300-306.

Tony, F. (2014, Jan 22). Sunflower microgreen nutrition information. Farmer Tony's mission greens. http://sproutingseedsoflove.com/nutriti on/sunflowermicrogreensproutsnutriti oninformation

Xiao, Z., Lester, G. E., Luo, Y., Xie, Z. K., Yu, L. L., \& Wang, Q. (2014b). Effect of light exposure on sensorial quality, concentrations of bioactive compounds and antioxidant capacity of radish microgreens during low temperature storage. Food chemistry, 151, 472-479.

Xiao, Z., Luo, Y., Lester, G. E., Kou, L., Yang, T. and Wang, Q. (2014a). Postharvest quality and shelf life of radish microgreens as impacted by storage temperature, packaging film, and chlorine wash treatment. $L W T$ Food Science and Technology, 55(2):551-558.

Zhu, Y., \& Gao, J. (2017). Effect of Package Film on the Quality of Postharvest Chinese Toon Tender Shoots Storage. Journal of Food Quality, 2017.

\section{How to cite this article:}

Nidhi Dalal, Saleem Siddiqui and Neeraj. 2020. Sensory Attributes of Sunflower Microgreens with Storage under Ethanol Vapour and Organic Acid Treatments. Int.J.Curr.Microbiol.App.Sci. 9(02): 208-214. doi: https://doi.org/10.20546/ijcmas.2020.902.026 